\title{
The Effect of Familiar and Fantasy Aesthetics on Learning and Experience of Serious Games
}

\author{
Erik D. van der Spek ${ }^{1}$, Tatiana Sidorenkova ${ }^{1}$, Paul Porskamp ${ }^{2}$, \\ and Matthias Rauterberg ${ }^{1}$ \\ ${ }^{1}$ Eindhoven University of Technology, PO Box 513 5600MB Eindhoven, The Netherlands \\ ${ }^{2}$ T-Xchange, PO Box 217 7522NB Enschede, The Netherlands \\ \{e.d.vanderspek, g.w.m.rauterberg\}@tue.nl, \\ tatyana.sidorenkova@gmail.com, paul.porskamp@txchange.nl
}

\begin{abstract}
Serious games have shown potential as learning material, but are not very engaging. One reason why games are considered to be fun is their ability to provide us with an interesting fantasy world to explore and play in, but this seems at odds with the more serious nature of formal training. In this study, a two by two (familiar versus unfamiliar visual setting and familiar versus unfamiliar story setting) single-blind experiment $(\mathrm{N}=60)$ was performed, testing the effect of the familiarity of aesthetics on game experience and learning. Significant effects of story condition on learning and game experience was found, with a familiar story setting leading to better learning, but subdued game experience. Other effects were not significant.
\end{abstract}

\section{Introduction}

Games are learning systems, and what makes a game fun is in part the pleasure derived from learning new patterns and being able to apply this new knowledge in solving problems [1]. It is therefore unsurprising that games are now also applied to learning and instruction of more serious materials (i.e. 'serious games'). After three decades of development and research, serious games have been found to be on average efficacious and in most cases even more so than traditional instruction [2, 3]. However, as [3] notes, much is still unknown on how serious games should be designed to be efficacious learning tools, and evidence for serious games to be more engaging is even wholly lacking.

\section{$2 \quad$ Fantasy and Familiarity}

Games are fun, among others, because they provide a fantasy setting, and invoke curiosity by showing virtual worlds that are alien or incongruous with everyday settings [4]. This however can be at odds with the more grounded demands of serious games, where it is the everyday setting or real world application that is regularly the object of study. It is often argued that the better games mimic the real world, the 
higher the transfer of learning [5]. Furthermore, learning is contingent on being able to link new information to existing prior knowledge in the long term memory [6] and while encountering an alien environment may foster curiosity, it may consequently be inefficient for learning, as the player is unable to integrate newly obtained game knowledge with prior knowledge obtained in the real world. From this one could argue that it is cognitively sound to have games with familiar, real world settings, though perhaps at the expense of engagement.

Conversely, the fantasy and curiosity that a game's fantasy setting affords, is also important for learning. It leads to more engagement with the learning material [4, 7], as well as more cognitive effort [8]. In previous research on serious games design, it was found that the inclusion of unexpected surprises in the narrative improved cognitive effort and subsequently deep comprehension of the instructional material, though not motivation [9]. Conversely, in other research the introduction of a curiosity inducing intervention led to more engagement, but not learning [10]. However, neither was focused on stimulating fantasy. Perhaps most critically, a game without fantasy is "simply an abstract context—a simulation of reality" [11]. Play occurs when someone steps into 'the magic circle', a place where disbelief is suspended and the player becomes immersed in an imaginary world [12]. Without some kind of fantasy that engages a player's imagination, play may not arise, and the serious game is less a game, and more training.

According to Schell, every game rests on four pillars: aesthetics, mechanics, technology and narrative [13]. For this research we tried to answer the question whether the aesthetics of a serious game should be familiar (i.e. corresponding with the real world), or a fantasy setting, in order to optimally stimulate learning and engagement. For this, we created four versions of an existing strategic decision-making (SDM) game, a picture of which can be seen in Figure 1.

The game was designed to train experts to make decisions based on incomplete or conflicting data and subsequently provide insight into their own decision-making process [14]. In the game, the player was confronted with a scenario about an important person that went missing. As the head of a crisis team, the player is tasked to make decisions based on advice that is provided by a number of experts in his or her team. In a $2 \times 2$ design, both the visual aesthetics and the story setting were either familiar or fantasy. The mechanics, technology and plot were kept the same.

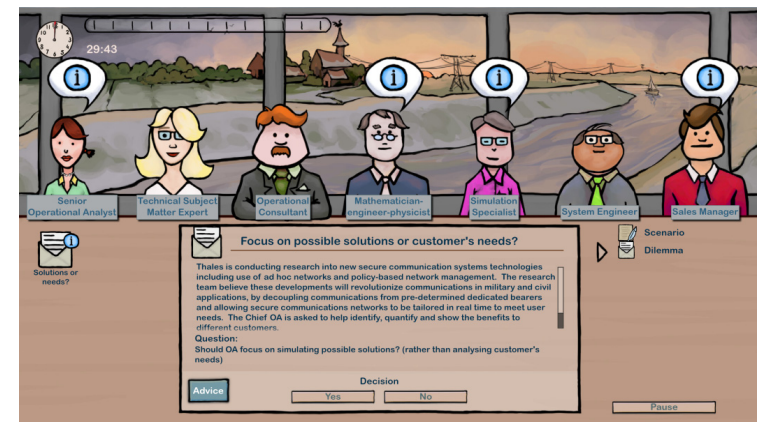

Fig. 1. Strategic Decision-Making game. Image and game courtesy of T-Xchange. 


\section{$3 \quad$ Method}

\subsection{Participants}

The strategic decision-making game was designed for experts (in this case operational analysts in a military setting). However, at the time of the experiment not enough experts in the field with a similar level of prior knowledge could be found for a large(r) scale study. Therefore, we opted for research with university students $(55 \%$ undergraduate, $45 \%$ graduate level). In total 60 participants, 33 males and 27 females within the age range of 18 to 41 years old $(\mathrm{M}=25.1, \mathrm{SD}=4.69)$ were recruited for the study. The majority of participants, $63.3 \%(\mathrm{~N}=38)$, played computer or/and video games. The participants were randomly assigned to one of the four conditions. As a reward for the participation, the participants received a coupon worth $€ 5.00$.

\subsection{Materials}

As the game was designed to train decision-making in dilemmas that did not have clear right or wrong answers, the learning goals were rather diffuse. Consequently as a measure for learning we used the Structural Knowledge Assessment (SKA) [15], which elicits a participant's knowledge structure about the game. This knowledge structure can then be compared to that of an expert, which results in a similarity score. For more explanation see [15], for the referent knowledge structure used to compare participant's knowledge structures against, see Figure 2.

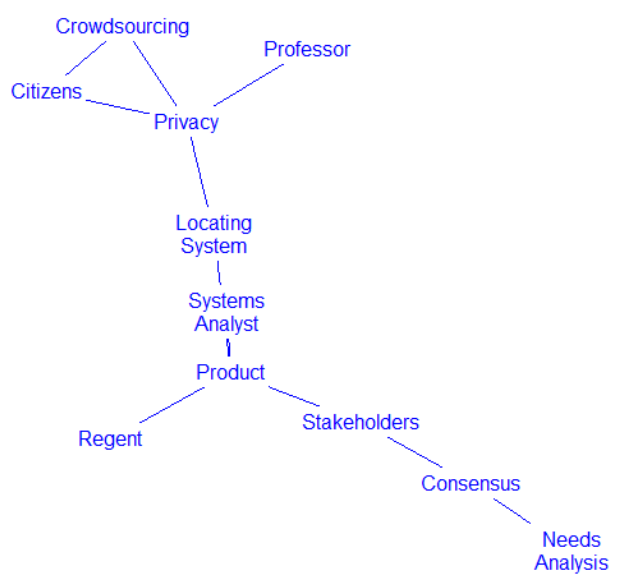

Fig. 2. Referent knowledge structure

In order to measure how involved the player was in the game, and to some extent how much of a game they felt the instructional material was, we used the Game Experience Questionnaire (GEQ) [16]. Lastly, a small knowledge test with 5 three item multiple choice questions was administered, that tested whether the participant remembered a few events in the game. This was mostly done as an extra check to determine the validity of the SKA. 


\subsection{Design}

The experiment was a $2 \times 2$ pretest posttest design, where the game's visual aesthetic was either familiar or fantasy, which was contrasted with the story being either contextualized in a familiar setting or a fantasy setting. See Figure 3.
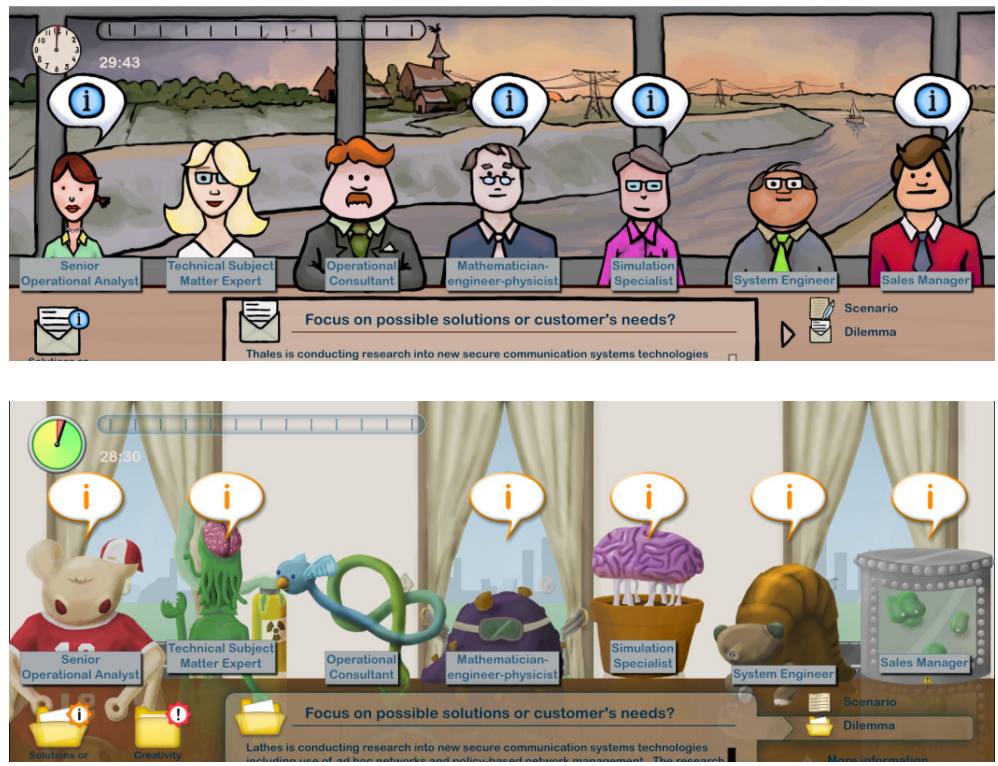

Solution: A social media tracking system including the citizens of Monacisch, their mobile phones and an app they could download. By law, the people of Monacisch are required to call in the King's location once they spot him without his security detail.
Solution: A mental computing system including the citizens of the planet Arraki, their brain and a mental computing app they could download. By law, the residents of Arraki are required to call in the location of the Holy Emperor once they spot him without his Holy Guards.

Fig. 3. Conditions of the game, top to bottom, left to right: familiar visual aesthetic, fantasy visual aesthetic, familiar story setting, fantasy story setting

\section{$4 \quad$ Results}

\subsection{Learning}

One outlier with IQR > 1.5 was removed from the familiar story condition, leading to valid $\mathrm{N}=59$. A $2 \times 2$ full factorial ANCOVA with post-intervention SKA as dependent variable, pre-intervention SKA as covariate and Story and Visual conditions as fixed factors, shows a significant main effect of Story on learning, $(F(1,54)=5.25, p<$ $\left.0.05, \eta_{\mathrm{p}}{ }^{2}=.089\right)$, with the familiar story setting leading to better learning than the 
fantasy story ( $M=0.097$ versus $M=0.57$ respectively). There was no significant main effect of Visual condition $(F(1,54)<1)$ and no significant interaction effect $(F(1,54)<1)$. If the outlier was not removed, the main effect of Story would have shown a trend: $\left(F(1,55)=2.84, p=0.098, \eta_{\mathrm{p}}{ }^{2}=.049\right)$.

\subsection{Game Experience}

A 2x2 MANOVA with the fourteen factors of the Game Experience Questionnaire (see section 3.2) as dependent variables and the conditions Story and Visuals as fixed factors, shows a significant main effect of Story on Game Experience Questionnaire (Wilk's $\lambda=0.52, F(3,43)=2.84, p<0.005$, multivariate $\eta^{2}=0.48$ ). Separate ANOVAs reveal that this is due to significant effects of condition on Negative Feelings $(F(1,56)=6.67, p<0.05)$, Positive Experience $(F(1,56)=8.18, p<0.01)$, Tiredness $(F(1,56)=9.10, p<0.005)$ and Returning to Reality $(F(1,56)=5.28, p<0.05)$. In all cases, ratings were higher in the fantasy story condition than in the familiar story condition. No significant main effect was found for the visual conditions, nor a significant interaction effect.

\section{$5 \quad$ Discussion and Future Work}

The results of the experiment indicate a catch 22 between learning and game experience in serious games, at least when it comes to the aesthetics of the game. Games with a fantasy environment offer a stronger game experience, but this is achieved at the cost of lower learning gains. If the learning goals of a serious game are the most important aspect, a more familiar setting should be used, but at the cost of a subdued game experience. This could give some explanation why serious games are efficacious though not very engaging [3]. Research on ways to circumvent this problem is therefore paramount.

It is also possible that fantasy aesthetics have an interaction effect with game mechanics, where a higher engagement could lead to a stronger will to engage with the game mechanics, i.e. gaming the system, but less to learning the information. This relationship should be scrutinized.

There are a number of other limitations to the research, which should also be clarified in future work. The learning in this game is very verbally focused, and less procedural. This could have an effect on the visual aesthetics conditions and pertaining results, where learning (and knowledge assessment) in our experiment was mostly on verbal knowledge, and subsequently the participants could have paid less attention to the visuals, leading to non-significant effects in the visual condition.

Furthermore, it could be argued that the setting and difficult task in the game were simply too alien for the players, that they needed some recognizable elements in order to engage with the game. Research by Kintsch and Mandler among others has highlighted that topics that are completely new for the learner will not lead to more cognitive interest [8]. This however seems at odds with the totally new fantasy offered by games. Future research will need to determine whether and where there is a middle ground of offering the right amount of fantasy, while tapping into the prior knowledge of the learner. 
Lastly, our experiment used novice participants. An expertise reversal effect is very much possible, where novices still struggle to generate schemata and therefore prefer familiar contexts to integrate new knowledge with prior knowledge, whereas experts already have relevant schemata and could prefer fantasy settings that challenge them in applying these. Therefore, research with experts is still very much needed.

\section{References}

1. Koster, R.: Theory of Fun for Game Design. O’Reilly Media, Inc. (2013)

2. Sitzmann, T.: A Meta-Analytic Examination of the Instructional Effectiveness of Computer-based Simulation Games. Pers. Psychol., 489-528 (2011)

3. Wouters, P., van Nimwegen, C., van Oostendorp, H., van der Spek, E.D.: A Meta-Analysis of the Cognitive and Motivational Effects of Serious Games. J. Educ. Psychol. 105, 249-265 (2013)

4. Malone, T.W.: Toward a theory of intrinsically motivating instruction. Cogn. Sci. 5, 333-369 (1981)

5. Alexander, A., Brunyé, T.: From gaming to training: A review of studies on fidelity, immersion, presence, and buy-in and their effects on transfer in pc-based simulations and games. In: I/ITSEC, pp. 1-14 (2005)

6. Mayer, R.E.: Designing Instruction for Constructivist Learning. In: Reigeluth, C.M. (ed.) Instructional-design Theories and Models, vol. 2, pp. 141-159. Erlbaum, Mahwah (1999)

7. Dickey, M.D.: Murder on Grimm Isle: The impact of game narrative design in an educational game-based learning environment. Br. J. Educ. Technol. 42, 456-469 (2011)

8. Campion, N., Martins, D., Wilhelm, A.: Contradictions and Predictions: Two Sources of Uncertainty That Raise the Cognitive Interest of Readers. Discourse Process. 46, 341-368 (2009)

9. van der Spek, E.D., van Oostendorp, H., Ch. Meyer, J.-J.: Introducing surprising events can stimulate deep learning in a serious game. Br. J. Educ. Technol. 44, 156-169 (2013)

10. Wouters, P., Van Oostendorp, H., Boonekamp, R., Van Der Spek, E.: The role of Game Discourse Analysis and curiosity in creating engaging and effective serious games by implementing a back story and foreshadowing. Interact. Comput. 23, 329-336 (2011)

11. Gunter, G.A., Kenny, R.F., Vick, E.H.: Taking educational games seriously: Using the RETAIN model to design endogenous fantasy into standalone educational games. Educ. Technol. Res. Dev. 56, 511-537 (2007)

12. Paras, B., Bizzocchi, J.: Game, motivation, and effective learning: An integrated model for educational game design. In: Proceedings of DiGRA 2005 (2005)

13. Schell, J.: The Art of Game Design: A book of lenses. CRC Press (2008)

14. http://www.txchange.nl/portfolio-item/mayors-game/

15. Wouters, P., Van der Spek, E.D., Van Oostendorp, H.: Measuring learning in serious games: a case study with structural assessment. Educ. Technol. Res. Dev. 59, 741-763 (2011)

16. Poels, K., de Kort, Y., IJsselsteijn, W.: It is always a lot of fun!: exploring dimensions of digital game experience using focus group methodology. In: Proceedings of the 2007 Conference on Future Play, pp. 83-89 (2007) 